\title{
Measurement of Firm IT Capability to Efficiently Perform Business Tasks in an IT Environment
}

\author{
Chui Young Yoon
}

\begin{abstract}
In an IT environment, enterprises have applied IT to their management and business activities. It is very important that a firm efficiently apply IT to its management activities and to improve the performance of tasks. The measurement and management for a firm IT capability need to improve the management and business performance in an IT environment. Perceived measures are necessary for a firm to gauge its IT capability, for it to manage and improve its IT capability. The first measurement items were developed from the research of previous literature and expert reviews. The 16-item scale was extracted by the validity and reliability analysis from the first generated measurement items. The developed tool can be utilized for efficiently measuring a firm IT capability in terms of a comprehensive IT capability.
\end{abstract}

Index Terms - Information technology (IT), firm it capability, measurement factor and item, measurement tool.

\section{INTRODUCTION}

Nowadays, enterprises are performing their management activities and business tasks in an IT environment. Most firms are applying IT (Information Technology) to the management and business activities for improving their business performance. They cannot efficiently perform the demands of global market without efficiently applying IT to their businesses. Enterprises have built information systems to raise business task performance and improve competitiveness [1]-[3]. IT is an important way to improve and preserve a firm's task performance in the ever-changing business environment [4]. In this environment, it is indispensable to apply IT to the business activities of a firm. Managing and building an IT environment appreciate for a firm is very important to improve an enterprise's IT ability for management activities and task performance. In order to manage and improve its IT environment, we need a scientific and objective tool that can measure its IT capability. Firm IT capability should be improved by objective criteria based on the measurement results. Previous study has barely studied such a tool to gauge firm IT capability. The enterprise's IT ability has only been researched from specific perspectives, not for a firm's entire IT capability [4]-[7]. That is, we need a measure that can gauge a firm ability of IT applications in terms of its general IT ability.

Hence, this study present a measurement scale that can

Manuscript received August 10, 2014; revised November 19, 2014. The research was supported by Basic Science Research Program through the National Research Foundation of Korea (NRF) funded by the Ministry of Education, Science and Technology (NO: 2013R1A1A2012350).

Chui Young Yoon is with the Department of IT Applied-Convergence, Korea National University of Transportation, Chungbuk, 368-701, South Korea (e-mail: yoon0109@ut.ac.kr). efficiently gauge a firm IT capability (FITC) for efficiently performing business tasks in an IT environment and for effectively establishing and improving its IT environment in a total IT ability perspective.

\section{PRevious STUdies}

In previous literature, many studies defined the definitions and major components of the IT capability from the view points of the researchers in previous studies [4]-[12]. IT capability is the aggregation of hardware, software, shared services, management practices, and technical and management skills [5], [6]. IT capability is described as the abilities to integrate other resources of organizations by using and allocating IT resources. IT resources are divided into three categories: IT infrastructure, IT human resources, and IT intangible assets [7]. IT capability can be divided into three capabilities: the capability of internal integration, the capability of business process redesign, and the capability of strategic revolution [8]. IT capabilities are defined as the confluence of abilities to allocate and manage IT resources and interact with other resources in organizations to affect commonly IT effectiveness and organizational goals, including IT infrastructure's capability and IT human resources skills [9]. IT capability means enterprise formation, transfer and deployment of enterprise information technology resources, support and improve other uniqueness functions that are competent at strength and skill, creating the latent potential for maintaining continuous competition advantages, including IT architecture and routine, IT infrastructure, IT human resources, IT relationship assets [10]. IT capability is portrayed as having three interrelated attributes: a fusion of business knowledge with IT knowledge, a flexible and reusable IT infrastructure, and an effective use process [11]. IT capability is a kind of organizational ability of mobilizing, deploying, integrating information resources combined with other enterprise resources and abilities to reach some certain goal, including IT infrastructure, IT management capability, and IT-business alignment capability [12].

IT competency is conceptualized as the extent to which a firm is knowledgeable about and effectively utilizes IT to manage information within the firm [6]. The components of IT competency represent three co-specialized resources [6]: IT objects; IT knowledge; and IT operations. IT objects represent computer-based hardware, software, and support personnel. IT knowledge is conceptualized as the extent to which a firm possesses a body of technical knowledge about objects such as computer based systems. IT operations are identified as the extent that a firm utilizes IT to manage market and customer information. 
From an information system (IS) perspective, the evaluation of the IS level indicates the total capability that includes IS vision, IS infrastructure, IS support, and IS application and usage [4], [13]. From researching these studies, we define the firm IT capability (FITC) as the total IT capability that a firm has to retain to efficiently support its management activities and perform tasks in an IT environment [4]-[13].

From researching previous literature, we extracted four core components of FITC: IT strategy (from IT strategy), IT knowledge (from IT knowledge), IT application (from IT operation), and IT infrastructure (from IT resources) [4]-[13]. They are the potential measurement factors of FITC in terms of a total IT capability of a firm. This research develops the first measurement items for FITC based on the definition and component of FITC and previous studies related on an enterprise's IT capability [4]-[13].

\section{METHOD}

This study generates the 31 measurement items for FITC based on definitions and components of IT capability in previous literature [4]-[13]. The developed items were reviewed and modified by the expert group in our IT research center: postdoctoral researchers, professors, and IT developers. We analyzed the construct validity of the developed items to ensure that FITC was efficiently measured by the items. Many studies presented various methods to verify the validation of a tool construct [14]-[17]. Generally, most studies present two methods of construct validation: (1) correlations between total scores and item scores, and (2) factor analysis [14]-[16]. The former assumes that the total score is valid, and the extent to which the item correlates positively with the total score is indicative of the construct's validity for the items [14]-[16]. Each item score was subtracted from the total score to exclude spurious part-whole correlation [14], [15]: the result was a corrected item-total that was then correlated with the item score. Factor analysis analyzes the underlying structure or components of the tool [16], [18], [19].

This study investigated a measure of criterion-related validity to identify items that did not show favorable or unfavorable attitudes. As all of the items in a measure are extracted from the domain of a single construct, responses to these items should be highly intercorrelated. The corrected item-total correlation presents a measure of this.

Our measurement questionnaire used a five-point Likert-type scale as presented in previous studies denoting, 1 : not at all; 2: a little; 3: moderate; 4: good and 5: very good. The questionnaire is composed of three major sections. The first section explains the backgrounds and objectives, the major contents, and response methods of this questionnaire. The second section asks respondents to provide general information, such as their business department and professional position, their academic qualifications, gender, age, and years of experience in their firms within an IT environment. The last section presents the measurement items for the respondents. This research collected data from a variety of industries and firms so that the results can be generalized. We used two kinds of survey methods: direct collection and e-mail. The respondents either directly mailed back the completed questionnaires or research assistants collected them 2-3 weeks later. The collected questionnaires represented 43 percent of the respondents.

\section{A. Sample Characteristics}

We collected 138 responses from our survey. They represented a variety of industries, enterprises, business departments and positions, and experience. This research excluded seven incomplete or ambiguous questionnaires, leaving 131 usable questionnaires for statistical analysis.

TABLE I: DEMOGRAPHIC CHARACTERISTICS OF THE RESPONDENTS

\begin{tabular}{|c|c|c|}
\hline Division & Total & Percentage \\
\hline \multicolumn{3}{|l|}{ Degree } \\
\hline Humanities \& Social Sciences & 20 & 15.3 \\
\hline Management \& Economics & 31 & 23.7 \\
\hline Engineering & 57 & 43.5 \\
\hline Science & 23 & 17.5 \\
\hline Total & 131 & 100 \\
\hline \multicolumn{3}{|l|}{ Industry } \\
\hline Manufacturing \& Processing & 13 & 9.9 \\
\hline Construction & 19 & 14.5 \\
\hline Finance, Banking \& Insurance & 22 & 16.8 \\
\hline $\begin{array}{l}\text { Transportation, Communication \& } \\
\text { Services }\end{array}$ & 36 & 27.5 \\
\hline $\begin{array}{l}\text { Information Consulting \& System } \\
\text { Implementation Services }\end{array}$ & 41 & 31.3 \\
\hline Total & 131 & 100 \\
\hline \multicolumn{3}{|l|}{ Business Department } \\
\hline Strategic Planning & 26 & 19.9 \\
\hline Development \& Maintenance & 31 & 23.6 \\
\hline Business Application & 53 & 40.5 \\
\hline Administrative Support & 21 & 16.0 \\
\hline Total & 131 & 100 \\
\hline \multicolumn{3}{|l|}{ Business Position } \\
\hline Senior Manager & 9 & 6.9 \\
\hline Middle Manager & 43 & 32.8 \\
\hline Worker & 79 & 66.3 \\
\hline Total & 131 & 100 \\
\hline
\end{tabular}

The respondent had on average of 10.4 years of experience (S.D. $=1.058$ ) in their field, their average age was 36.4 years old (S.D. $=5.436$ ), and their gender, male $(75.4 \%)$ and female $(24.6 \%)$. The survey method used in this measurement questionnaire was based on two kinds of collection methods: by direct collection and e-mail. Our survey was intentionally targeted at various industries and managers above the middle management level within an enterprise for two reasons. First, FITC significantly contributes to greater effectiveness in a wide range of industries and companies. Second, in order to increase the generalizability of our research results, we used a diverse sample that thoroughly understands their FITC, as a result of working at high management levels within their enterprise for more than 10 years.

Hence, the respondents can effectively provide the right and proper responses for our questionnaire survey.

\section{B. Factor and Reliability Analysis}

This research used factor analysis and reliability analysis to verify and reliability the validity of the framework construct and items. These analyses were also used to identify the underlying factors or components that comprise the FITC construct. Inadequate items for the tool were deleted based on the analysis results. We considered sufficiently high criteria to extract adequate measures of FITC.

Based on these analyses, the first 31 measurement items 
were reduced to 16 items, with 15 items were deleted. The elimination was sufficiently considered to ensure that the retained items were adequate measures of FITC. The validity and reliability of the tool were verified by factor analysis and reliability analysis. These deletions resulted in a 16-item scale to measure FITC. One factor with Eigen value $=7.9$ explained as explaining $63 \%$ of the variance. Each of the 16 items had factor loadings $>0.590$ and reliability coefficients (Cronbach's alpha) of four potential factors had the values $>$ 0.786 . Table I shows the analysis results of the 16 items.

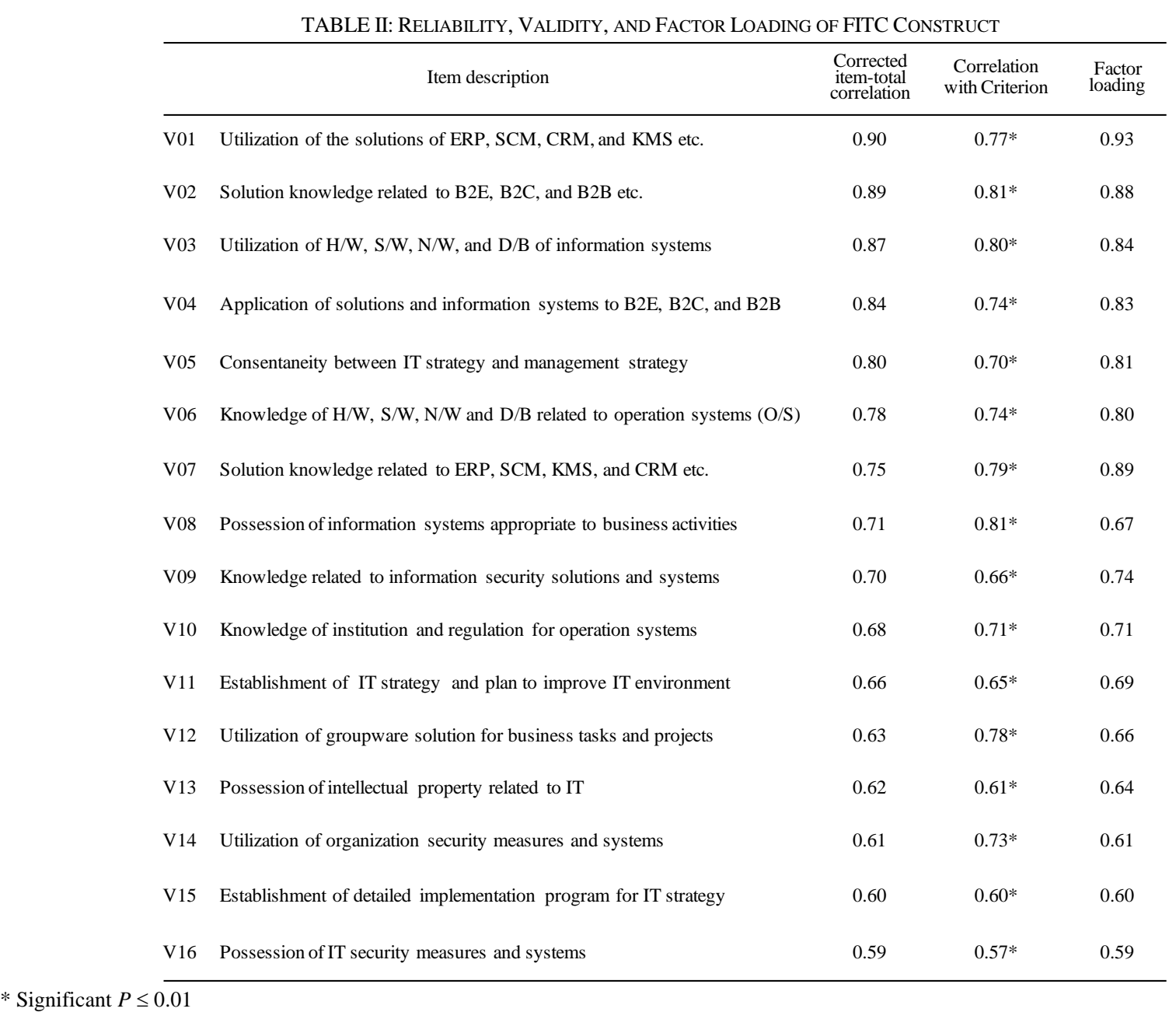

We calculated the corrected item-total correlations between each variable and its corresponding factor to examine the reliability and validity of the measures. They are all in the acceptable range. Most corrected item-total correlations were greater than 0.590 , showing that the measures are good indicators of their corresponding factors in Table II. Hence, the extracted items have a validity and reliability in terms of a measurement construct. They are the potential measurement items of FITC in terms of the whole IT capability of a firm. Hence, the extracted items have a validity and reliability in terms of a measurement construct. Based on the results of factor and reliability analyses as presented in Table II and III, we can categorize the groups as follows: factor 1 (V5, V11, V15); factor 2 (V2, V06, V07, V09, V10); factor 3 (V01, V03, V04, V12, V14); and factor 4 (V08, V13, $\mathrm{V} 16)$. They are the potential measurement factors of FITC in terms of the total IT capability of a firm.

\section{Construct Validity}

We verified the construct validity of the developed tool. Construct validity is used to examine how well the results obtained from using the measure fit with the theories that lie behind the design of the instrument. There are two common forms of construct validity, convergent and discriminant validity [20], [21]. This research uses two methods to confirm the construct validity of FITC: 1) the correlation matrix approach to investigate construct validity of the developed FITC measure [22]; 2) correlation coefficients between each dimension of FITC scale and average score of the FITC scale.

TABLE III: CORRELATION MATRIX OF FITC MEASURES

\begin{tabular}{|c|c|c|c|c|c|c|c|c|c|c|c|c|c|c|c|c|}
\hline V2 & 0.58 & & & & & & & & & & & & & & & \\
\hline V3 & 0.51 & 0.53 & & & & & & & & & & & & & & \\
\hline V4 & 0.31 & 0.39 & 0.37 & & & & & & & & & & & & & \\
\hline V5 & 0.32 & 0.36 & 0.31 & 0.54 & & & & & & & & & & & & \\
\hline V6 & 0.33 & 0.31 & 0.34 & 0.47 & 0.50 & & & & & & & & & & & \\
\hline V7 & 0.39 & 0.33 & 0.37 & 0.51 & 0.48 & 0.57 & & & & & & & & & & \\
\hline V8 & 0.35 & 0.36 & 0.41 & 0.48 & 0.54 & 0.57 & 0.55 & & & & & & & & & \\
\hline V9 & 0.34 & 0.39 & 0.33 & 0.30 & 0.38 & 0.31 & 0.34 & 0.34 & & & & & & & & \\
\hline V10 & 0.39 & 0.31 & 0.33 & 0.32 & 0.37 & 0.38 & 0.33 & 0.32 & 0.48 & & & & & & & \\
\hline V11 & 0.31 & 0.29 & 0.32 & 0.33 & 0.37 & 0.30 & 0.33 & 0.38 & 0.53 & 0.49 & & & & & & \\
\hline $\mathrm{V} 12$ & 0.29 & 0.33 & 0.34 & 0.37 & 0.31 & 0.32 & 0.33 & 0.34 & 0.51 & 0.58 & 0.59 & & & & & \\
\hline $\mathrm{V} 13$ & 0.32 & 0.37 & 0.27 & 0.30 & 0.31 & 0.34 & 0.37 & 0.38 & 0.50 & 0.61 & 0.55 & 0.60 & & & & \\
\hline V14 & 0.28 & 0.34 & 0.30 & 0.34 & 0.31 & 0.34 & 0.32 & 0.33 & 0.32 & 0.31 & 0.29 & 0.31 & 0.37 & & & \\
\hline V15 & 0.32 & 0.31 & 0.38 & 0.36 & 0.31 & 0.34 & 0.32 & 0.37 & 0.35 & 0.33 & 0.30 & 0.31 & 0.32 & 0.51 & & \\
\hline \multirow[t]{2}{*}{ V16 } & 0.30 & 0.28 & 0.34 & 0.35 & 0.33 & 0.32 & 0.37 & 0.36 & 0.35 & 0.33 & 0.38 & 0.37 & 0.36 & 0.56 & 0.53 & \\
\hline & V1 & v2 & v3 & V4 & V5 & V6 & v7 & v8 & v9 & V10 & V11 & V12 & V13 & V14 & V15 & V16 \\
\hline Mean & 3.13 & 2.78 & 2.49 & 3.35 & 3.14 & 2.97 & 2.93 & 3.08 & 2.71 & 2.59 & 2.63 & 2.56 & 2.98 & 2.71 & 3.14 & 3.31 \\
\hline S.D. & 1.48 & 1.36 & 1.35 & 1.29 & 1.33 & 1.34 & 1.31 & 1.28 & 1.33 & 1.34 & 1.26 & 1.31 & 1.34 & 1.27 & 1.32 & 1.19 \\
\hline
\end{tabular}


In the correlation matrix methods, this research examines convergent validity by determining whether relationships between scales of the same factor are higher than zero and large enough to execute discriminant validity analysis [23]. We also examine discriminant validity by counting the number of times that an item had a higher correlation with items of other factors than with those of its own factor [19]. The correlation matrix shows only five violations for 398 potential comparisons.

Additionally, we also analyzed the correlations between them to investigate the relationship between the IT strategy, IT knowledge, IT application, IT infrastructure, and FITC, as indicated in Table IV. From the analysis results, FITC had high correlation with each factor in the matrix, and a highest correlation with IT application. IT infrastructure was more highly correlated with IT strategy than with IT utilization. The results suggest that the FITC construct is an important instrument to measure and explain FITC from IT strategy to IT infrastructure.

\begin{tabular}{lccccc}
\multicolumn{6}{c}{ TABLE IV: CORRELATION MATRIX } \\
\hline & & $(2)$ & $(3)$ & $(4)$ & $(5)$ \\
\hline FITC & $(1)$ & 0.43 & 0.54 & 0.62 & 0.42 \\
IT Strategy & $(2)$ & & 0.48 & 0.56 & 0.53 \\
IT Knowledge & $(3)$ & & & 0.58 & 0.48 \\
IT Application & $(4)$ & & & & 0.46 \\
IT Infrastructure & $(5)$ & & & & \\
\hline
\end{tabular}

\section{DISCUSSION}

We need to measure the FITC in order to grasp the present status of a firm's IT capability and examine how its management activities and business performance in an IT environment could be improved. The FITC affects a firm's management activities and competitiveness. But it is difficult to effectively gauge FITC in terms of a total IT capability. This research maybe contributes to making progress on this problem. There are some limitations to our study in terms of a broad enough range of data from a variety of industries and firms. Our research focuses on finding efficient methods and directions to build a firm IT capability in an entire IT ability perspective, which can efficiently support its management activities and improve business performance, through measuring FITC by reliable and valid framework. The overall measurement elements for FITC are the items presented in Table II. The items were identified by using four factor groups as the potential factors for measuring FITC. By exploring the measurement items of each potential factor based on previous studies and the export review, this research classified the four potential factors as follows: factor 1: IT strategy (V5, V11, V15); factor 2: IT knowledge (V02, V06, V07, V09, V10); factor 3: IT application (V01, V03, V04, V12, V14); and factor 4: IT infrastructure (V08, V13, V16). These items include the overall measurement content for FITC, from IT strategy to IT infrastructure. Namely, these measures refer to a scale that gauges FITC in terms of the whole IT capability. Since there are the factors affecting FITC and the firm's management activities and business performance in an IT environment, the utilization of the developed tool can efficiently improve a firm's IT capability. The developed measures may be appropriate for the type of environment where firms use IT for their management activities, and especially where the output performance is important. FITC is as critical as actual management ability in terms of its effect on the firm's overall IT capability. Hence, understanding the FITC construct is very important. Although many studies have focused on IT utilization capability, IT integration ability, IT aggregation, IT internal integration, and continuous competitive advantages, research on FITC from an entire IT capability perspective has been lacking. Previous studies have rarely considered the relationship between FITC and its major factors. But understanding this relationship is critical for its success. The developed measures may be used for FITC across different industrial fields and business departments, and could even serve as a global measure.

\section{Structure of Measurement ToOl}

This study identified into four factor groups based on the factor analysis. The factor groups mean the potential factors as major components measuring FITC. By prior research, we identified the following four core factors: factor 1: IT strategy; factor 2: IT knowledge; factor 3: IT application; and factor 4: IT infrastructure. These extracted factors comprise the overall measurement content for FITC from IT strategy to IT infrastructure. Namely, this means a tool that measure FITC in terms of a total IT capability from IT strategy to infrastructure, including four measurement factors and 16 items as indicated in Fig. 1.

That is, understanding the FITC structure is essential to measure the success of FITC that denotes the total IT capability to efficiently support its management and business activities. We can use the comprehensive scale to measure FITC across different industrial fields and business departments, and perhaps even as a global measure.

\section{A. Measurement Factors and Items}

This tool has IT strategy, IT knowledge, IT application, and IT infrastructure as the core measurement factors, and 16-measurement items as the measurement elements, as presented in Fig. 1. Major factors of this framework have the meanings and measurement elements as follows.

IT strategy means a firm's consistent IT plan and program based on the management strategy for present and future. It has IT strategy and plan, and information implementation plan, to effectively advance FITC. It comprises the items that can gauge IT strategy related to the consentaneity between IT strategy and management strategy, the establishment of IT strategy and plan to improve IT environment, and the establishment of a detailed IT implementation program for IT strategy.

IT knowledge indicates the technical knowledge that a firm has to retain such as information technology, IT solutions and applications, and information systems and infrastructure. It connotes the items that can measure application knowledge (B2B, B2C, and B2E etc.), knowledge related to hardware, software, networks, and databases, solution knowledge (ERP, SCM, CRM, and KMS etc.), knowledge related to security 
measures, and institution and regulation for operation systems.

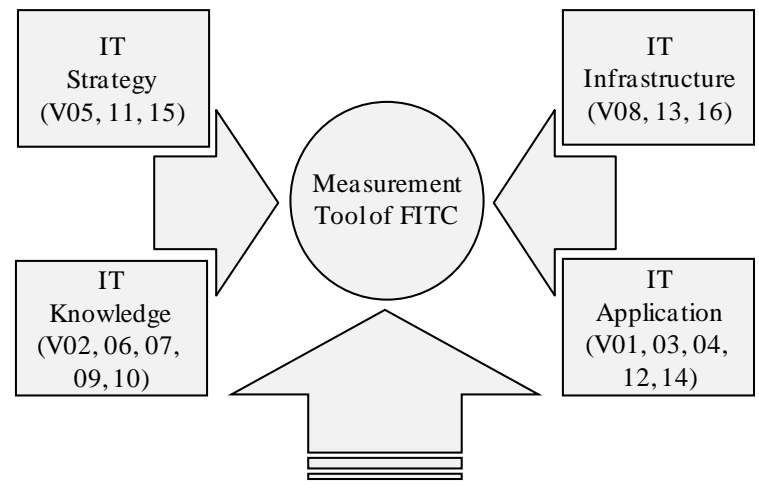

\section{IT Strategy (ITS)}

V05: Consentaneity between IT strategy and management strategy

V11: Establishment of IT strategy and plan to improve IT environment

V15: Establishment of detailed implementation program for IT strategy

IT Knowledge (ITK)

V02: Application knowledge related to B2E, B2C, and B2B etc.

V06: Knowledge of H/W, S/W, N/W and D/B related to operation systems

V07: Solution knowledge related to ERP, SCM, KMS, and CRM etc.

V09: Knowledge related to information security solutions and systems

-V10: Knowledge of institution and regulation for operation systems

IT Application (ITA)

V01: Utilization of solutions of ERP, SCM, CRM, and KMS etc.

V03: Utilization of H/W, S/W, N/W, and D/B of information systems

V04: Application of solutions and systems to B2E, B2C, and B2B

-V12: Utilization of groupware solutions for business tasks and projects

V14: Utilization of organization security measures and systems

IT Infrastructure (ITI)

V08: Possession of information systems appropriate to business activities

V13: Possession of intellectual property related to IT

-V16: Possession of IT security measures and systems

Fig. 1. Structure of the measurement tool with factors and items.

IT application represents a firm's ability to apply IT knowledge, IT solutions and applications, and information systems to management activities to efficiently execute its management activities and business tasks. It contains the application abilities as follows: utilization of solutions of ERP, SCM, CRM, and KMS etc., utilization of H/W, S/W, N/W, and $\mathrm{D} / \mathrm{B}$, application of solutions and information systems to $\mathrm{B} 2 \mathrm{E}, \mathrm{B} 2 \mathrm{C}$, and B2B, utilization of groupware solutions for business tasks and projects, and utilization of organizational security measures and systems.

IT infrastructure refers to IT resources, such as information system, intellectual property, and IT security measures and systems. They have an effect on developing and improving FITC. It has the items that can measure firm IT infrastructure: possession of information systems appropriate to business activities, intellectual property related to IT, and IT security measures and systems. This is the crucial factor for the development of IT environment and resources to develop and improve the firm's IT ability. As indicated in Fig. 1, the measurement scale is a critical theoretical construct to measure the FITC that a firm can efficiently perform its management activities and business tasks in an IT environment.

\section{CONCLUSION}

This study presented a practical framework that can measure a comprehensive FITC from a total IT perspective. The developed tool with adequate validity and reliability provides groundwork for the development of a standard measure of FITC. Although this scale has additional limitations in terms of measuring specific aspects of FITC, it means a reliable and valid construct that can effectively measure FITC. The approaching research in terms of a whole IT capability of a firm is very important to reasonably raise the organizational total efficiency and optimization for its management and business in an IT environment. The findings can be also utilized in increasing a firm's capability of IT applications and building IT environment appropriate for the firm's management activities and business tasks in order to enlarge its business performance and competitiveness.

Therefore, this study finds an efficient direction and foundation for developing the comprehensive tool for measuring FITC in an IT environment. In future research, we will provide advanced research and analysis results through applying the developed tool to case studies for a variety of actual enterprises.

\section{ACKNOWLEDGMENT}

This research was supported by Basic Science Research Program through the National Research Foundation of Korea (NRF) funded by the Ministry of Education, Science and Technology (NO: 2013R1A1A2012350).

\section{A. Measurement Items for Firm IT Capability}

1) Consentaneity between IT strategy and management strategy?

2) Preparation and consistency of an information strategy plan and vision?

3) Preparation of a detailed IT implementation program for IT strategy?

4) Establishment of IT strategy and plan to improve IT environment?

5) Preparation of resource allocation schemes for an IT plan?

6) Establishment of detailed implementation program for IT strategy?

7) Preparation of analysis and countermeasures for IT risk components?

8) Preparation of development and improvement of information systems for future management?

9) Solution knowledge related to ERP (Enterprise Resource Planning), SCM (Supply Chain Management), CRM (Customer Relationship Management), and KMS (Knowledge Management Systems) etc.?

10) Knowledge related to information security solutions and systems?

11) Technical knowledge for the development and implementation of information systems and IT resources?

12) Knowledge related to hardware, software, networks, and databases?

13) Application knowledge related to $\mathrm{B} 2 \mathrm{E}$ (Business-to-Employee), B2C (Business-to-Customer), and B2B (Business-to-Business)?

14) Intellectual property related to IT for enterprise information systems? 
15) Knowledge of institution and regulation for operation systems?

16) Utilization of individual and group scheduling?

17) Sharing and integration of information between business departments?

18) Utilization of decision support systems?

19) Utilization of solutions such as ERP, SCM, CRM, and KMS etc.?

20) Utilization of $\mathrm{H} / \mathrm{W}, \mathrm{S} / \mathrm{W}, \mathrm{N} / \mathrm{W}$, and $\mathrm{D} / \mathrm{B}$ of information systems?

21) Application of solutions and information systems to B2E, $\mathrm{B} 2 \mathrm{C}$, and B2B?

22) Utilization of Executive Information Systems (EIS)?

23) Utilization of groupware solutions for business tasks and projects?

24) Utilization of organization security measures and systems?

25) Construction of firewall and security systems?

26) Possession of information systems appropriate to management activities?

27) Implementation of a Database Management System (DBMS) and a data warehouse?

28) Possession of intellectual property related to IT?

29) Construction of an efficient website for management activities and organization?

30) Possession of IT security measures and systems?

31) Possession of IT personnel appropriate for information systems?

\section{REFERENCES}

[1] P. J. Rondeau, T. S. Ragu-Nathan, and M. A. Vonderembse, "How involvement, IS management effectiveness, and end-user computing impact IS performance in manufacturing firms," Information \& Management, vol. 43, pp. 93-107, 2006.

[2] A. Bhattacherjee, "Understanding information systems continuance: An expectation-confirmation model," MIS Quarterly, vol. 25, no. 3, pp 351-370, 2001

[3] C. Y. Yoon, "Development of a measurement model of personal information competency in information environment," The Korea Society of Information Processing and Systems, vol. 14-D, no. 1, pp. 131-138, 2007

[4] C. S. Leem and K. S. Kim, "Introduction to an integrated methodology for development and implementation of enterprise information systems," The Journal of Systems and Software, vol. 60, pp. 249-261, 2002.

[5] W. R. King, "IT capability, business process, and impact on the bottom line," Journal of Information System Management, vol. 19, no. 2, pp. 85-87, 2002.

[6] L. Wang and P. Alam, "Information technology capability: Firm valuation, earnings uncertainty, and forecast accuracy," Journal of Information Systems, vol. 21, no. 2, pp. 27-49, 2007.

[7] A. S. Bharadwaj, "A resource-based perspective on information technology capability and firm performance: An empirical investigation," MIS Quarterly, vol. 24, no. 1, pp. 169-196, 2000.

[8] G. Fang, X. B. Wu, and Z. Y. Wu, "The dynamic information technology capability and firm performance: A resource-based perspective," presented at the Fifth International Conference on Machine Learning and Cybernetics, Dalian, China, 2005.
[9] M. J. Tippins and R. S. Sohi, "IT competency and firm performance: Is organizational learning a missing link," Strategic Management Journal, vol. 24, pp. 745-761, 2003.

[10] H. Jiao, C. Chang, and Y. Lu, "The relationship on information technology capability and performance: An empirical research in the context of China's Yangtze River delta region," in Proc. the IEEE International Conference on Industrial Engineering and Engineering Management, pp. 872-876, 2008.

[11] Q. Cheng, R. Zhang, and Y. Tian, "Study on information technology capabilities based on value net theory," in Proc. the international Symposium on Electronic Commerce and Security, pp. 1045-1050, 2008.

[12] Z. Qingfeng and Z. Daqing, "The impact of IT capability on enterprise performance: An empirical study in China," WiCOM 2008, pp. 1-6, 2008.

[13] J. Peppard and J. Ward, "Beyond strategic information systems: Towards an IS capability," Journal of Strategic Information Systems, vol. 13, pp. 167-194, 2004.

[14] G. Torkzadeh and W. J. Doll, "The development of a tool for measuring the perceived impact of information technology on work," Omega, International Journal of Measurement Science, vol. 27, pp. 327-339, 1999.

[15] R. McHancy, R. Hightower, and J. Pearson, "A validation of end-user computing satisfaction instrument in Taiwan," Information \& Management, vol. 39, pp. 503-511, 2002.

[16] G. Torkzadeh and J. W. Lee, "Measures of perceived end-user's information skills," Information \& Management, vol. 40, pp. 607-615, 2003.

[17] F. N. Kerlinger, Foundations of Behavioral Research, McGraw-Hill, New York, 1978.

[18] Y. F. Wen, "An effectiveness measurement model for knowledge management," Knowledge-Based Systems, vol. 22, no. 5, pp. 363-367, 2009.

[19] K. Klenke, "Construct measurement in management information systems: A review and critique of user satisfaction and user involvement instruments," INFOR, vol. 30, no. 4, pp. 325-348, 1992.

[20] P. J. Hu, P. Y. K. Chau, O. R. Liu Sheng, and K. Y. Tam, "Examining the technology acceptance model using physician acceptance of telemedicine technology," Journal of Management Information Systems, vol. 16, no. 2, pp. 91-112, 1999.

[21] C. Y. Yoon, "A comprehensive instrument for measuring individual competency of IT applications in an enterprise IT environment," IEICE Trans on Information and Systems, vol. E95-D, no. 11, pp. 2651-2657, 2012.

[22] P. C. Palvia, "A model and instrument for measuring small business user satisfaction with information technology," Information and Management, vol. 31, no. 3, pp. 151-163, 1996.

[23] A. M. Aladwani and P. C. Palvia, "Developing and validating an instrument for measuring user web quality," Information and Management, vol. 39, no. 6, pp. 467-476, 2002.

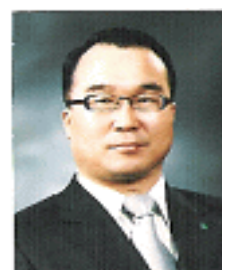

Chui Young Yoon received the Ph.D. degree in computer science \& industrial system engineering from Yonsei University, Seoul, South Korea in 2003. He worked as a professor at Seoul Cyber University for 2003-2005 and an associate professor at College of Electrical \& Computer Engineering in Chungbuk National University for 2006-2010, and is a professor at the Department of IT-Applied Convergence in Korea National University of Transportation, Chungju City, Chungbuk, South Korea. He has registered in Marquis Who's Who in the World/Science and Engineering (2009-2012), "Great Minds of the 21st Century" (2010-2012), ABI, and "Outstanding Intellectuals of the 21 st Century" (2010-2012), IBC. He has participated as the TPC member and section chair of IEEE IEEM, ICMIT, CSCWD international conferences. His research interests include information system, knowledge-based systems, and measurement of individual competency, human-computer interaction, web-based system and ubiquitous computing technology. 